\title{
What is the limit of sustained swimming in Atlantic salmon post smolts?
}

\author{
Malthe Hvas*, Ole Folkedal, Frode Oppedal \\ Animal Welfare Research Group, Institute of Marine Research, Matre 5984, Norway
}

\begin{abstract}
A trend in Atlantic salmon aquaculture is to establish new production sites that are susceptible to extreme weather conditions; however, strong and persistent water currents may compromise fish welfare. Defining acceptable current conditions necessitates an assessment of sustained swimming abilities that are fuelled solely by aerobic metabolism and do not result in fatigue. In this study, the limit of sustained swimming was quantified with regards to both speed and time in Atlantic salmon of $\sim 700 \mathrm{~g}$ and $\sim 39 \mathrm{~cm}$ at $12^{\circ} \mathrm{C}$ by testing fish in groups of 10 in a large swim tunnel respirometer. First, critical swimming speed $\left(U_{\text {crit }}\right)$ $\left(107 \mathrm{~cm} \mathrm{~s}^{-1}\right)$ and minimum cost of transport $(66 \mathrm{~cm}$ $\mathrm{s}^{-1}$ ) were measured. Sustained swimming trials at constant speeds were then performed based on a percentage of the group mean $U_{\text {crit }}(80,85,90,95$, 100 or $105 \%$ ). Fish were forced to swim until they fatigued or until $72 \mathrm{~h}$ had passed. Surprisingly, most fish were able to sustain 80 and $85 \% U_{\text {crit }}$ for 72 consecutive hours. However, at the highest speeds, fatigue was reached within the first $2 \mathrm{~h}$. By categorizing fatigue times of individual fish into $<2$, $2-72$ or $>72 \mathrm{~h}$, significant differences in relative swimming speeds were found that corresponded to $2.7,2.5$ and 2.2 body lengths $\mathrm{s}^{-1}$, respectively. These results document impressive sustained swimming capacities in farmed Atlantic salmon and add important temporal insights about ambient current limits with regards to fish welfare at exposed aquaculture sites.
\end{abstract}

KEY WORDS: Critical swimming speed · Endurance swimming · Exposed aquaculture · Fish welfare $\cdot$ Swim tunnel respirometry

${ }^{*}$ Corresponding author: malthe.hvas@imr.no

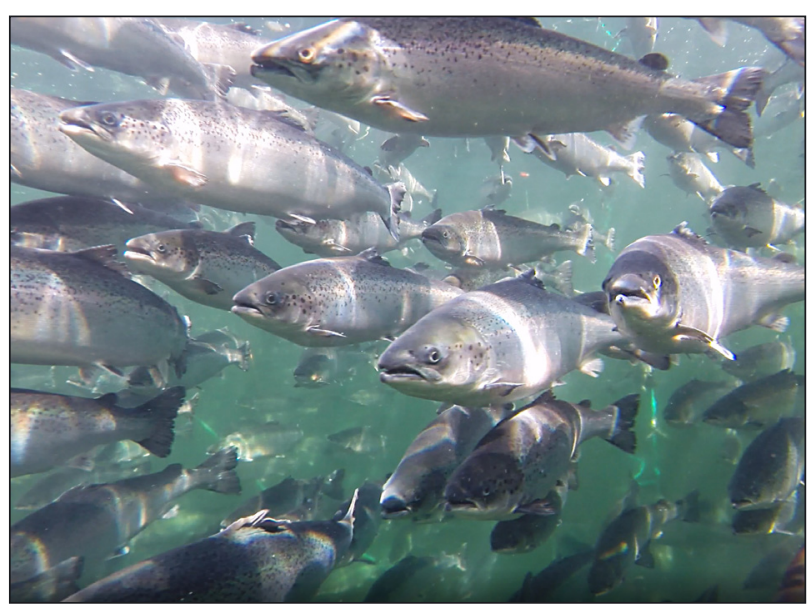

Atlantic salmon swimming against the current inside a sea cage. New offshore farm sites are exposed to strong currents, which may become a welfare concern if swimming limits are exceeded.

Photo: Frode Oppedal

\section{INTRODUCTION}

The Atlantic salmon Salmo salar aquaculture industry is currently seeking to establish production at exposed locations that are susceptible to extreme weather conditions such as strong water currents and powerful waves (Holmer 2010, Bjelland et al. 2015, Gentry et al. 2017). This process requires technological advancements and novel management strategies and, more importantly, thorough assessments of whether the fish can thrive in harsher environments. Since strong and persistent water currents are considered the greatest threat to fish welfare at exposed aquaculture sites, recent efforts have focussed on de-

() The authors 2021. Open Access under Creative Commons by Attribution Licence. Use, distribution and reproduction are unrestricted. Authors and original publication must be credited. 
veloping guidelines for acceptable current conditions based on the behavioural and physiological impacts on Atlantic salmon (Hvas et al. 2021a). In calm weather or low currents, farmed Atlantic salmon swim in circles in the cages at speeds chosen by the fish themselves (Johansson et al. 2007, Oppedal et al. 2011). However, if the current speed exceeds this preferred swimming speed, the salmon will stop cruising and instead maintain position in the current while swimming at a speed dictated by the environment (Johansson et al. 2014, Hvas et al. 2017a). This forced increase in swimming speed may lead to welfare concerns since voluntary behaviours become restricted. Moreover, long-term exposure to moderately high current conditions above the preferred swimming speed may compromise growth since the fish need to divert substantial energy towards continuous swimming efforts (Farrell et al. 1991, Solstorm et al. 2015). The spontaneous preferred swimming speed of Atlantic salmon and other species reflects the migratory nature of wild specimens and has been linked to the minimum cost of transport (CoT) (Weihs et al. 1981, Tudorache et al. 2011, Hvas et al. 2017a). The minimum CoT is achieved at a swimming speed that minimizes energy use per distance travelled and is measured using swim tunnel respirometry (Ohlberger et al. 2006, Palstra et al. 2008, McKenzie et al. 2021). If the experimental conditions used to measure minimum CoT are representative of growing salmon in sea cages, this metric may provide a theoretical baseline for tolerable constant water currents at exposed aquaculture sites owing to its link with voluntary swimming behaviours (Hvas et al. 2017a).

In the event of very high current speeds, the fish need to increase their swimming efforts accordingly. Eventually, this may lead to physiological exhaustion where locomotory control is lost, causing the fish to collide with the net wall which likely will result in injuries (Remen et al. 2016). Furthermore, the acidbase and endocrine disturbances caused by exhaustive exercise can kill salmonids (Black 1958, Wood et al. 1983).

To define the maximum tolerable peak currents at exposed aquaculture sites, the critical swimming speed $\left(U_{\text {crit }}\right)$ has been proposed as a suitable welfare indicator (Remen et al. 2016). Similar to CoT, $U_{\text {crit }}$ is most often measured using swim tunnel respirometry and is obtained by a stepwise increase in current speed until the fish being tested reach fatigue (Brett 1964). $U_{\text {crit }}$ thereby represents the maximum prolonged swimming speed that can be maintained for a limited duration and is fuelled by both aerobic and anaerobic metabolism (Wilson \& Egginton 1994).
Owing to tidal currents and strong winds, peak currents at exposed sites may persist for several hours or days, whereas $U_{\text {crit }}$ only can be maintained for minutes. Therefore, it is necessary to assess the capacity for high-intensity swimming that does not result in fatigue. This is termed 'sustained swimming' and is powered solely from aerobic slow red muscle fibres while the fast white anaerobic fibres remain inactive (Hudson 1973, Bone et al. 1978). Contrary to $U_{\text {crit, }}$ sustained swimming should, in theory, not result in fatigue since lactate buildup is avoided and homeostasis is maintained.

For pragmatic reasons, sustained swimming has often been defined as speeds that can be maintained for $200 \mathrm{~min}$ (Beamish 1978). However, few studies have tested fish for such long durations (e.g. Brett 1967, Cotterell \& Wardle 2004, Palstra et al. 2008, Hvas \& Oppedal 2017). To identify the limit of sustained swimming in fish, it is instead more common to find the point of transition from aerobic to a mixture of aerobic and anaerobic metabolism in shorter $U_{\text {crit }}$ tests, and this indirect approach suggests that in salmonids this limit is $70-90 \%$ of the $U_{\text {crit }}$ (Kiceniuk \& Jones 1977, Burgetz et al. 1998, Beddow \& McKinley 1999). Recently, it was confirmed that Atlantic salmon post smolts can sustain $80 \%$ of their $U_{\text {crit }}$ for $4 \mathrm{~h}$ while maintaining constant oxygen uptake rates, indicating that swimming efforts remained strictly aerobic (Hvas \& Oppedal 2017).

To evaluate whether Atlantic salmon can be farmed responsibly at exposed aquaculture sites, it is essential to collect information on maximum current speeds and their duration. To date, only 1 study has evaluated an extensive time series of water current data at exposed aquaculture sites from a fish welfare perspective (Jónsdóttir et al. 2019). In that study, it was found that strong currents above $60 \mathrm{~cm} \mathrm{~s}^{-1}$ occasionally persisted for up to $5 \mathrm{~h}$, which is higher than the preferred swimming speeds of growing Atlantic salmon post smolts (Hvas et al. 2017a) but less than their presumed sustained swimming limit (Hvas \& Oppedal 2017).

To our knowledge, sustained swimming limits above the $4 \mathrm{~h}$ mark have not yet been explored in salmonids. Furthermore, while the aetiology of fatigue in $U_{\text {crit }}$ tests is the inability to maintain adequate energy production per time unit, another type of fatigue may be encountered during constant swimming for very long periods owing to depletion of metabolite supply (Jones 1982). Hence, Atlantic salmon may also eventually become fatigued despite swimming within their aerobic capacity. 
The purpose of this study was to quantify the limit of sustained swimming in Atlantic salmon post smolts with regards to both speed and time. This was done by subjecting fish to a series of swim trials at constant speeds above the minimum CoT based on a percentage of the $U_{\text {crit }}$ until fatigue was reached or $72 \mathrm{~h}$ of swimming had been endured.

\section{MATERIALS AND METHODS}

\subsection{Animal husbandry}

Atlantic salmon post smolts (Aquagen) were kept in large indoor holding tanks (diameter: $3 \mathrm{~m}$; volume: $5.3 \mathrm{~m}^{3}$ ) at the Matre Research Station, Institute of Marine Research, Norway. The holding tanks were supplied with filtered, aerated, and UV-C treated seawater (34 ppt) in an open-flow system (120 l $\min ^{-1}$ ) which maintained oxygen saturation above $85 \%$ at all times and prevented $\mathrm{CO}_{2}$, ammonia and other waste products from accumulating. The water temperature was maintained at $12^{\circ} \mathrm{C}$ by controlled mixing from ambient and heated water supplies. A simulated natural photoperiod was provided, and the fish were fed commercial feed $(4.5 \mathrm{~mm}$ pellet size; Skretting) in excess each day via automated feeders. The fish were acclimated to these conditions for a minimum of 1 mo before the experimental trials began.

The use of animals in the present study was approved by the Norwegian Food Safety Authorities under permit identification number 23196.

\subsection{Swim tunnel setup}

A large swim tunnel respirometer designed to assess swimming behaviour in groups of larger salmonids was used for all swim trials in the present study and has been thoroughly described (Remen et al. 2016, Hvas et al. 2017b). Briefly, the cylindrical swim section was $248 \mathrm{~cm}$ long and $36 \mathrm{~cm}$ in diameter and the entire volume of the setup was 1905 l. The top lid at the downstream end of the swim section could be removed for access when fish had to be either placed into or removed from the tunnel. A camera was placed behind the rear grid of the swim section, allowing for remote observation of the fish during the swim trials. An oxygen sensor (RINKO ARO-FT; JFE Advanced) was located next to the camera and was programmed to log oxygen concentration at $2 \mathrm{~s}$ intervals (MiniSoft SD200W; SAIV En- vironmental Sensors \& Systems). Desired current speeds were generated with a motor-driven propeller (Flygt 4630, $11^{\circ}$ propeller blade; Xylem Water Solutions), after carefully calibrating motor output with its corresponding flow speed using a flow meter (Höntzsch Flow Measuring Technology). Before entering the swim chamber section of the setup, the water flow would enter a resting chamber, a honeycomb to straighten the flow (cell diameter of $5 \mathrm{~mm}$ ), and a reduction cone (diameter reduced from 65 to $36 \mathrm{~cm}$ ). This setup was designed to minimize turbulence and provide approximately laminar flow conditions during the swim trials. Water was supplied into the swim tunnel via a large pipe connected to the same header tank that supplied water to the holding tanks. A continuous moderate open flow through the swim tunnel system ensured a stable temperature of $12^{\circ} \mathrm{C}$ as well as normoxic conditions. When oxygen uptake rates $\left(\mathrm{MO}_{2}\right)$ were being measured, the water supply could be closed off and subsequently opened again for rapid flushing with a maximum capacity of $2701 \mathrm{~min}^{-1}$ to quickly reestablish oxygen levels.

There are several advantages with testing groups of fish in a large swim tunnel rather than individual fish in a small swim tunnel. For instance, smaller flumes may artificially inhibit $U_{\text {crit }}$ by restricting natural swimming behaviours such as burst and glide swimming (Tudorache et al. 2007, Remen et al. 2016). Group testing in larger setups also allows for more individuals to be tested within a reasonable time and is a better approximation of real aquaculture conditions (Hvas \& Oppedal 2019, Palstra et al. 2020). Furthermore, swimming in schools can provide hydrodynamic benefits in some species (Herskin \& Steffensen 1998, Svendsen et al. 2003), although in Atlantic salmon specifically, $U_{\text {crit }}$ was unaffected by swimming in groups compared to swimming alone in the swim tunnel system used in the present study (Hvas \& Oppedal 2019).

\subsection{Experimental design and protocol}

In the introductory part of the experiment the purpose was to establish a representative average $U_{\text {crit }}$ and the minimum CoT of the fish in the holding tanks. Here, 10 fish were netted and quickly transferred to the swim tunnel, which was in the same room as the holding tanks. The fish were then allowed to acclimate to their new environment in the swim tunnel at a modest current speed of $15 \mathrm{~cm}$ $\mathrm{s}^{-1}$ until the following morning when the swim trial commenced. The swim trial protocol consisted of a 
stepwise increase in current velocity of $15 \mathrm{~cm} \mathrm{~s}^{-1}$ every $30 \mathrm{~min}$. Eventually, the fish would struggle to swim against the current, and the point of fatigue was defined when they became trapped on the rear grid and were unable to regain a swimming position, despite being encouraged to do so with tactile stimulation. Elapsed time was then recorded, and the fish were removed from the swim tunnel and immediately euthanized with a blow to the head, and fork length and weight were measured. The swim trial continued until all fish had reached fatigue and replicated 3 times to provide 30 individual $U_{\text {crit }}$ measurements. To measure $\mathrm{MO}_{2}$ during these swim trials, the system was closed off for 20 min and then flushed for 10 min in each increment interval. In these temporarily closed periods, the oxygen saturation never dropped below $85 \%$, even at the higher current speeds. In addition, the tail beat frequency was recorded in 4 random fish at each swimming interval by manually counting the time required to perform 100 tail beats.

The main part of the experiment consisted of sustained swimming trials where fish were forced to swim at constant speeds based on a percentage of the mean $U_{\text {crit }}$ obtained. Similarly to the $U_{\text {crit }}$ swim trials, fish were transferred to the tunnel the day before being tested to allow for overnight acclimation at a current speed of $15 \mathrm{~cm} \mathrm{~s}^{-1}$. The sustained swim trials were started by gradually increasing the current speed by $15 \mathrm{~cm} \mathrm{~s}^{-1}$ every 5 min until the target speed was reached. When individual fish became fatigued, as described in the $U_{\text {crit }}$ trials, they were removed from the swim tunnel and euthanized, and elapsed time was recorded along with fish size parameters. The sustained swim trials were continued for up to $72 \mathrm{~h}$, and if any fish were still swimming at this time, they were noted to have completed the test and removed as described above. Dimmed light was present at night to allow for remote observation of swimming status via the camera deployed in the swim tunnel. In addition, the camera feed was streamed so that observations could be continued via other devices throughout the night. This allowed the experimenter to go home in the evenings, and if any fish started to struggle with maintaining position, the laboratory could be reached in less than $10 \mathrm{~min}$, which allowed the experimenter to be present at the time any fish reached fatigue. Sustained swimming trials at 6 linearly increasing test speeds were completed as the main part of the experiment, which corresponded to $80,85,90,95,100$ and $105 \%$ of the mean $U_{\text {crit }}$.

\subsection{Data analyses}

$U_{\text {crit }}$ was calculated according to Brett (1964):

$$
U_{\text {crit }}=U_{f}+\frac{t_{f} U_{i}}{t_{i}}
$$

were $U_{f}$ is the highest completed current speed $(\mathrm{cm}$ $\left.\mathrm{s}^{-1}\right), U_{i}$ is the increment speed $\left(15 \mathrm{~cm} \mathrm{~s}^{-1}\right), t_{f}$ is the time endured at the final speed before fatiguing (min) and $t_{i}$ is the increment interval (30 min). Owing to a large cross-sectional area in the swim section relative to the size of the fish being tested, solid blocking effects were not corrected for in the reported $U_{\text {crit }}$ values, as this effect would have been minimal (Bell \& Terhune 1970, Hvas \& Oppedal 2019). The $\mathrm{MO}_{2}$ was calculated in each closed period of the $U_{\text {crit }}$ trials from the linear decrease in oxygen concentration over time as:

$$
\dot{\mathrm{MO}_{2}}=\frac{\frac{\Delta \mathrm{O}_{2}}{\Delta t}\left(V_{\mathrm{sys}}-V_{b}\right)}{W_{b}}
$$

where $\Delta \mathrm{O}_{2} / \Delta t$ is the change in oxygen concentration over time, $V_{\text {sys }}$ is the volume of the system, $V_{b}$ is the volume of the fish where a density of $1 \mathrm{~kg} \mathrm{l}^{-1}$ is assumed, and $W_{b}$ is the weight of the fish. The CoT at different swimming speeds was derived from $\mathrm{MO}_{2}$ and is expressed as $\mathrm{mg} \mathrm{O} \mathrm{O}_{2} \mathrm{~kg}^{-1} \mathrm{~km}^{-1}$. A quadratic regression was then fitted to the CoT versus swimming speed; the minimum of this function was defined as the minimum CoT. Background respiration was not corrected for, as this effect was found to be insignificant during pilot trials owing to the high volume to surface area ratio of this large swim tunnel system. The condition factor of each fish was calculated according to Ricker (1975) as $100\left(W / L_{f}^{3}\right)$, where $W$ is the body weight (in $g$ ) and $L_{f}$ is the fork length (in $\mathrm{cm}$ ).

Where appropriate, 1-way ANOVA along with Tukey's post hoc test was used to test for differences between groups after having confirmed equal variance and normality with Levene's mean test and the Shapiro-Wilk test, respectively. Pearson productmoment correlation was used to assess potential correlations between $U_{\text {crit }}$ and fish length; $\mathrm{p}<0.05$ was considered significant, and data are reported as means \pm SE unless specified otherwise.

\section{RESULTS}

The weight, fork length, and condition factor of each treatment group are shown in Table 1. All fish came from the same holding tanks and were tested 
Table 1. Size parameters for the Atlantic salmon swimming trials, showing mean $( \pm \mathrm{SE})$ weight, fork length, condition factor $(K)$ and number of fish measured (n) in each treatment group. Different superscript letters indicate a significant difference $(\mathrm{p}<0.05 ; 1$-way ANOVA with Tukey's post hoc test)

\begin{tabular}{|lllll|}
\hline \multicolumn{7}{|c|}{ Weight $(\mathrm{g})$} & Length $(\mathrm{cm})$ & \multicolumn{1}{c|}{$K$} & $\mathrm{n}$ \\
\hline$U_{\text {crit }}$ trials & $667 \pm 23^{\mathrm{ab}}$ & $38.4 \pm 0.4^{\mathrm{ab}}$ & $1.17 \pm 0.02$ & 30 \\
$80 \% U_{\text {crit }}$ & $656 \pm 26^{\mathrm{ab}}$ & $38.7 \pm 1.1^{\mathrm{ab}}$ & $1.13 \pm 0.03$ & 10 \\
$85 \% U_{\text {crit }}$ & $767 \pm 24^{\mathrm{ab}}$ & $40.9 \pm 0.5^{\mathrm{a}}$ & $1.12 \pm 0.01$ & 10 \\
$90 \% U_{\text {crit }}$ & $592 \pm 44^{\mathrm{b}}$ & $37.1 \pm 0.7^{\mathrm{b}}$ & $1.14 \pm 0.04$ & 10 \\
$95 \% U_{\text {crit }}$ & $770 \pm 34^{\mathrm{ab}}$ & $40.8 \pm 0.76^{\mathrm{a}}$ & $1.13 \pm 0.02$ & 10 \\
$100 \% U_{\text {crit }}$ & $787 \pm 56^{\mathrm{a}}$ & $40.0 \pm 1.2^{\mathrm{ab}}$ & $1.21 \pm 0.02$ & 10 \\
$105 \% U_{\text {crit }}$ & $783 \pm 39^{\mathrm{ab}}$ & $40.6 \pm 0.6^{\mathrm{ab}}$ & $1.16 \pm 0.02$ & 10 \\
\hline
\end{tabular}

within a fairly short time frame, therefore the sizes were similar between groups, except for the $90 \%$ $U_{\text {crit }}$ group, which had lower weight than the $100 \%$ $U_{\text {crit }}$ group and lower fork length than the 85 and $95 \% U_{\text {crit }}$ groups (ANOVA, df $=89, \mathrm{p}<0.001$ in all cases). The average size of all tested fish was $705.4 \mathrm{~g}$ in weight, $39.2 \mathrm{~cm}$ in fork length and 1.16 in condition factor, and the achieved fish density in the swim tunnel ranged from $23.5-31.2 \mathrm{~kg} \mathrm{~m}^{-3}$, with a mean density of $28.0 \mathrm{~kg} \mathrm{~m}^{-3}$ across all trials.

$U_{\text {crit }}$ was $107.3 \pm 1.2 \mathrm{~cm} \mathrm{~s}^{-1}$, which corresponded to $2.80 \pm 0.04$ body lengths $\mathrm{s}^{-1}$. In Fig. $1 \mathrm{~A}$, the $U_{\text {crit }}$ of individual fish is shown as a function of fork length. Fork length did not significantly correlate with $U_{\text {crit }}$ within the range of sizes tested here (Pearson, $\mathrm{R}^{2}=$ $0.129, \mathrm{p}=0.498, \mathrm{n}=30$ ). The minimum CoT speed, as derived from the minimum of a quadratic regression fitted to CoT versus swimming speed, was $65.9 \mathrm{~cm} \mathrm{~s}^{-1}$ (1.72 body length $\mathrm{s}^{-1}$ ), corresponding to $\sim 61 \%$ of the $U_{\text {crit }}$ (Fig. 1B). $\mathrm{MO}_{2}$ increased exponentially with swimming speed (Fig. 1C), and the tail beat frequency increased linearly with increasing swimming speed, from $1.41 \pm 0.03$ beats s $\mathrm{s}^{-1}$ at $30 \mathrm{~cm} \mathrm{~s}^{-1}$ up to $3.65 \pm 0.27$ beats s${ }^{-1}$ at $105 \mathrm{~cm} \mathrm{~s}^{-1}$ (Fig. 1D).

The sustained swimming limit expressed as a percentage of the group mean $U_{\text {crit }}$ is shown in Fig. 2A. The amount of time the fish were able to maintain constant swimming increased with decreasing test speeds. Specifically, in the 105 and $100 \% U_{\text {crit }}$ groups, the mean fatigue times were $0.56 \pm 0.11$ and $0.94 \pm 0.12 \mathrm{~h}$, and all fish had reach fatigue within
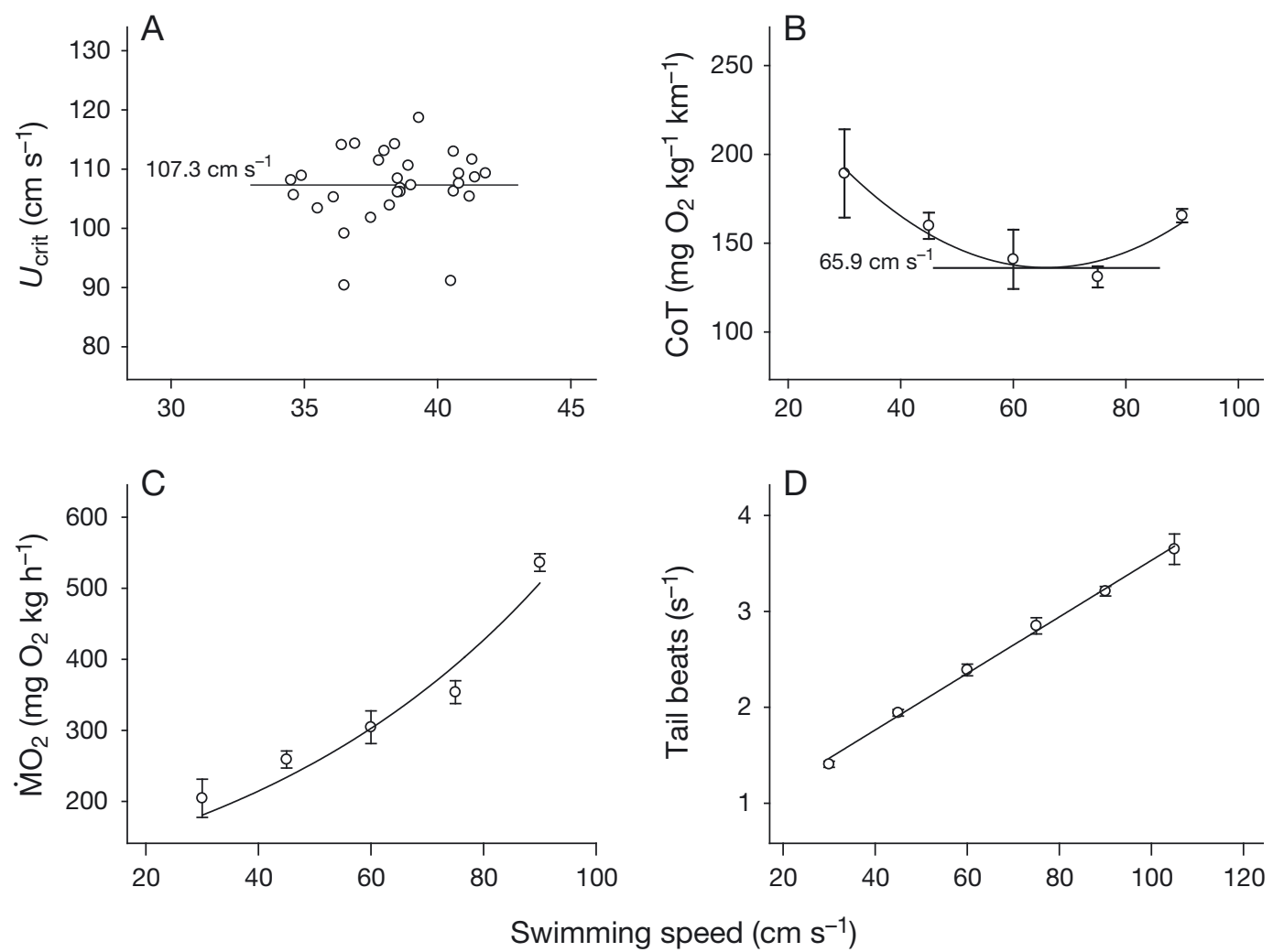

Fig. 1. (A) Critical swimming speed $\left(U_{\text {crit }}\right)$ versus fork length of Atlantic salmon; horizontal line: group mean. (B) Cost of transport (CoT) at different swimming speeds; fitted quadratic regression and horizontal line intersect at the minimum CoT. (C) Oxygen uptake rate $\left(\mathrm{MO}_{2}\right)$ and (D) tail beat frequency as a function of swimming speed. Data in (B), (C) and (D) are means $\pm \mathrm{SE}$ 

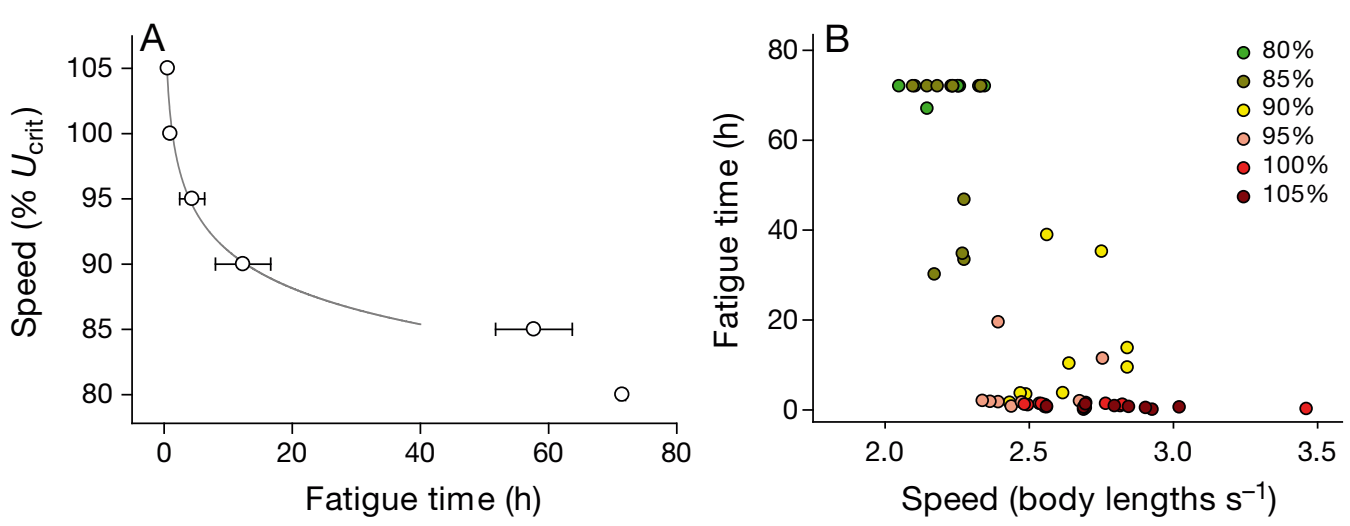

Fig. 2. Sustained swimming limits in Atlantic salmon, showing (A) time required to reach fatigue at constant swimming speeds based on a percentage of the group mean critical swimming speed ( $U_{\text {crit }}$ ). A power function is fitted to those treatment groups where all the fish fatigued $\left(y=101.18 x^{-0.046}, \mathrm{R}^{2}=0.974\right)$; data are means \pm SE. (B) Fatigue time of individual fish swimming at constant speed derived from a percentage of the group mean $U_{\text {crit }}$ when expressed as their relative swimming speeds (body lengths s${ }^{-1}$ ). Different colours correspond to a percentage of $U_{\text {crit. }}$. Swim tests were stopped after $72 \mathrm{~h}$ in those cases where fish did not become fatigued; therefore, values do not represent a threshold

1.25 and $1.36 \mathrm{~h}$, respectively. In the 95 and $90 \% U_{\text {crit }}$ groups, the mean fatigue times were $4.37 \pm 0.20$ and $12.3 \pm 4.3 \mathrm{~h}$, and the best swimmers were able to endure 19.5 and $38.9 \mathrm{~h}$, respectively. At the lowest test speeds of 85 and $80 \% U_{\text {crit, }}$ no fish became fatigued within the first $24 \mathrm{~h}$. Moreover, 9 out of 10 fish in the $80 \% U_{\text {crit }}$ group and 6 out of 10 fish in the $85 \%$ $U_{\text {crit }}$ group endured $72 \mathrm{~h}$ of constant swimming without reaching fatigue. Here, the worst swimmers fatigued after $30.1 \mathrm{~h}$ in the $85 \% U_{\text {crit }}$ group and after $67 \mathrm{~h}$ in the $80 \% U_{\text {crit }}$ group.

In Fig. 2B, the fatigue time of each fish is shown as a function of their corresponding relative swimming speed (body lengths $\mathrm{s}^{-1}$ ) in the sustained swim trials.

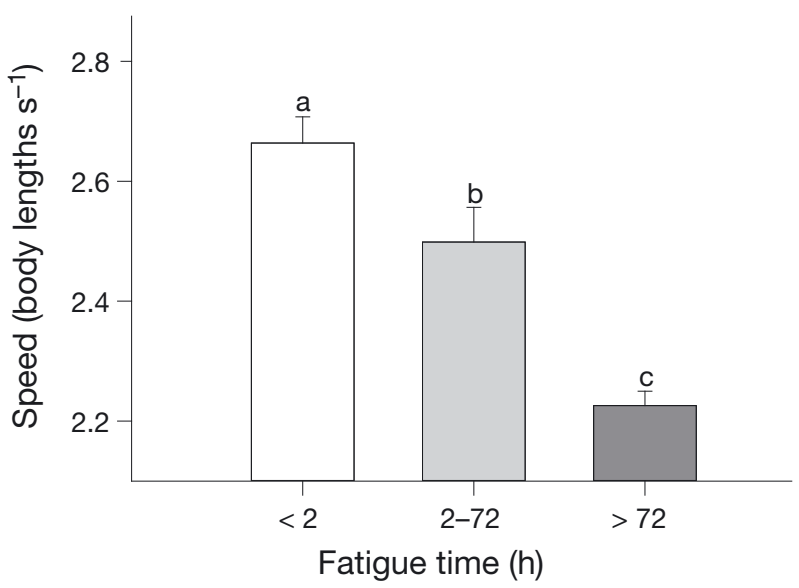

Fig. 3. Mean $( \pm \mathrm{SE})$ categorized fatigue times of Atlantic salmon. Fish are divided into 3 groups based on their fatigue times, with $\mathrm{n}=29$ for the $<2 \mathrm{~h}$ group, $\mathrm{n}=16$ for the $2-72 \mathrm{~h}$ group and $\mathrm{n}=15$ for the $>72 \mathrm{~h}$ group. Different letters indicate significant differences $(p<0.05)$ in relative swimming speed between groups
There was minimal overlap in relative swimming speeds between fish that endured the entire trial and fish that fatigued within the first few hours, with a notable divide at $\sim 2.3$ body lengths $\mathrm{s}^{-1}$. Hence, all fish that fatigued early were swimming above 2.3 body lengths $\mathrm{s}^{-1}$, while fish that endured $72 \mathrm{~h}$ were swimming at or below 2.3 body lengths $\mathrm{s}^{-1}$ (Fig. 2B). Furthermore, by categorizing the fish into 3 groups based on their fatigue times, significant differences in relative swimming speeds were found between fish that endured less than $2 \mathrm{~h}(2.66 \pm 0.04$ body lengths $\left.\mathrm{s}^{-1}\right)$, between 2 and $72 \mathrm{~h}(2.50 \pm 0.06$ body lengths $\left.\mathrm{s}^{-1}\right)$, and above $72 \mathrm{~h}(2.23 \pm 0.02$ body lengths $\mathrm{s}^{-1}$ ) (ANOVA, df = 59, p < 0.001) (Fig. 3).

\section{DISCUSSION}

\subsection{Limit of sustained swimming}

The limit of sustained swimming in Atlantic salmon has been estimated to be $80-85 \%$ of the $U_{\text {crit }}$ as inferred from the point of transition between strictly aerobic to a mixture of aerobic and anaerobic metabolism (Beddow \& McKinley 1999, Hvas \& Oppedal 2017). However, to our knowledge, whether such high-intensity aerobic swimming eventually results in fatigue has not been previously investigated. In the present study, we found that Atlantic salmon post smolts swimming close to their aerobic limit were able to sustain continuous swimming for more than $72 \mathrm{~h}$ without becoming fatigued, while fish swimming above the aerobic limit (e.g. $>85 \% U_{\text {crit }}$ ) all reached fatigue, generally within the first few hours 
and more rapidly at the higher test speeds. Hence, there appears to be a fine line between sustained and unsustained swimming, here exemplified as $\sim 2.3$ body lengths $\mathrm{s}^{-1}$, where below this limit swimming can be maintained for very long periods.

Fatigue in fixed velocity tests is thought to be caused by substrate depletion rather than the failure to supply energy at a sufficient rate while maintaining homeostasis (Jones 1982). However, surprisingly, $72 \mathrm{~h}$ at 80 or $85 \% U_{\text {crit }}$ did not trigger this effect in most of the fish tested. This demonstrates an impressive capacity for endurance swimming in farmed Atlantic salmon and shows that previous estimates of the transition to partly anaerobic metabolism provide good proxies for sustained swimming limits on longer timescales than previously assessed.

A fish swimming near its aerobic limit for several days, as in the present study, will need to feed at some point. Ingestion and digestion of food imposes an additional metabolic burden and alters systemic blood flow distribution, which also may impair swimming performance (Randall \& Daxboeck 1982, Alsop \& Wood 1997, Farrell et al. 2001). In theory, feeding during swimming near the aerobic limit will push the fish into the anaerobic zone and fish therefore cannot swim indefinitely at this speed. Hence, a definition of sustained swimming that also allows fish to feed and grow while swimming at their upper limit should also be considered when assessing sustained swimming limits at very long timescales (e.g. weeks). In Atlantic salmon, such thresholds would likely be above the minimum CoT ( 60\% $\left.U_{\text {crit }}\right)$, where additional aerobic capacity remains to support the metabolic costs of feeding, but below the transition to partly anaerobic swimming ( $\left.80-85 \% U_{\text {crit }}\right)$, where the entire aerobic capacity is permanently exhausted.

Considering the treatment groups tested above the aerobic limit (i.e. 90, 95, 100, and 105\% $U_{\text {crit }}$ ), an interesting pattern emerged where the average time to fatigue decreased exponentially as the test speed increased. This neatly reflects the energetics of swimming. For instance, $\mathrm{MO}_{2}$ increases approximately exponentially, or theoretically more precisely as a power function, with increasing swimming speed until the maximum aerobic metabolic rate is reached (Norin \& Clark 2016). This is due to hydrodynamics, as drag forces increase in proportion to the square of the speed, and the power required to overcome drag thus increases with the cube of the speed (Webb 1975, Videler 1993). It therefore becomes energetically expensive to further increase swimming efforts. Moreover, if the maximum aerobic metabolic rate has already been reached, additional energy needs to be supplied anaerobically, meaning that the anaerobic burden rapidly accumulates with modest further increases in swimming speeds. In the present study, this explains why time to fatigue drastically decreased as test speeds increased in those treatment groups where anaerobic metabolism was required to support swimming efforts.

\subsection{Implications for exposed aquaculture}

Our assessment of sustained swimming limits of fish in fixed velocity tests for up to $72 \mathrm{~h}$ is substantially longer than any previous work on salmonids that we are aware of. The interest in swimming limits at longer timescales has emerged only recently with the trend towards exposed offshore salmon aquaculture (Bjelland et al. 2015, Hvas et al. 2021a). In these harsher farm environments, prolonged periods of inescapably fast water currents may occur and become a serious fish welfare concern (Remen et al. 2016). Furthermore, knowledge of swimming capacities at different timescales is required when evaluating ocean data from site surveys for potential new farm sites (e.g. Jónsdóttir et al. 2019). However, for wild fish, as well as farmed fish in conventional aquaculture settings, such extended test durations are probably of limited relevance since these fish can generally choose their preferred swimming speed.

In earlier work on fish subjected to swim trials that lasted for days or weeks, the focus was primarily on growth performance and not swimming capacity (Christiansen \& Jobling 1990, Brown et al. 2011, Castro et al. 2011, Palstra et al. 2015, Solstorm et al. 2015). The highest swimming speeds investigated have therefore only been of moderate intensity and typically below the minimum CoT. An underlying assumption in these studies has been that exercise regimes may enhance growth and provide health benefits, and such positive effects have indeed often been reported in several finfish aquaculture species (reviewed by McKenzie et al. 2021).

However, above a certain threshold, the growth performance will decrease owing to the energetic burden of continuous swimming (Farrell et al. 1991, Solstorm et al. 2015). Specifically, Atlantic salmon post smolts maintained in raceways for $6 \mathrm{wk}$ and constant swimming speeds of 1.5 body lengths $\mathrm{s}^{-1}$ showed reduced growth rates compared to fish at lower speeds (Solstorm et al. 2015). Here, it is important to consider scaling effects when interpreting swimming speeds reported in body lengths $\mathrm{s}^{-1}$, as the 
relative swimming capacity of fish decreases with size (Brett 1965, Hvas et al. 2018). Hence, Solstorm et al. (2015) tested smaller fish starting at $98.6 \mathrm{~g}$ and $22.3 \mathrm{~cm}$, and the minimum CoT of similar-sized Atlantic salmon was determined to be 2 body lengths $\mathrm{s}^{-1}$ (Oldham et al. 2019), while the minimum CoT of substantially larger fish was 1.67 body lengths s ${ }^{-1}$ in the present study. Interestingly, the test speed of 1.5 body lengths $\mathrm{s}^{-1}$ used by Solstorm et al. (2015) was most likely below the minimum CoT, yet growth was mildly impaired. In contrast, a recent study found improved growth when Atlantic salmon with initial sizes of $83 \mathrm{~g}$ and $19.3 \mathrm{~cm}$ were kept at 2.5 body lengths $\mathrm{s}^{-1}$ over a 3 mo period when compared to lower speeds (Timmerhaus et al. 2021). Considering that this treatment was likely higher than the speed for minimum CoT, and more so in the latter part of the experiment owing to scaling effects, this result was surprising. However, while growth improved, fish welfare decreased, as indicated by inflamed muscle fibres, gill lesions and fin damage, thus it can be misleading to only focus on growth performance when defining minimum environmental conditions (Timmerhaus et al. 2021). Nevertheless, considering the extended definition of sustained swimming discussed above, life can be sustained at and slightly above the speed for minimum CoT. However, such conditions will not be ideal from an aquaculture production perspective owing to the risk of reduced production performance and various negative welfare impacts (Solstorm et al. 2015, Timmerhaus et al. 2021) Moreover, it will likely also become difficult to administer feed efficiently in sea cages if currents remain rough and horizontal fish distribution becomes skewed (Johansson et al. 2014).

Regarding welfare guidelines for exposed aquaculture, the present work adds novel temporal insights into the endurance swimming capacities of farmed Atlantic salmon. Most importantly, periods of persistent strong water currents that do not exceed the aerobic swimming limit should be endurable by the fish until calmer conditions resume. However, current speeds approaching the $U_{\text {crit }}$ will likely result in fatigue within minutes or hours.

Another factor to consider when interpreting welfare guidelines derived from small-scale laboratory swim trials is that Atlantic salmon in commercial sea cages form massive schooling structures where notable current damping occurs within the cage and downstream (Johansson et al. 2007, 2014, Gansel et al. 2014, Klebert \& Su 2020). Individual fish could theoretically switch position to the rear end of the group if swimming requirements upfront become too strenuous. However, it is presently unclear whether farmed Atlantic salmon can exploit positional benefits during group swimming. Hence, individual variation in positioning within schools and their relation to swimming efforts in exposed sea cages would be a highly relevant topic in future studies.

In addition to scaling with fish size, the swimming abilities of Atlantic salmon are also modulated by a range of environmental and health-related factors such as water temperature, hypoxia, and parasites (Bui et al. 2016, Hvas et al. 2017b,c, Oldham et al. 2019). For instance, the present study was performed at $12^{\circ} \mathrm{C}$, which is close to the optimal range for swimming performance in Atlantic salmon (Hvas et al. 2017b); moreover, the fish were in excellent health because they were maintained in a controlled laboratory environment with a sterilized water supply. Hence, the swimming limits reported here may overestimate the capabilities of Atlantic salmon in commercial sea cages that are subject to less optimal conditions and prevailing diseases and parasites.

For management purposes at exposed farm sites, camera observations of fish behaviours can provide good indicators of real-time swimming status in the ambient environment e.g. though recordings of swimming speeds (provided ambient currents are corrected for), tail beat frequency and overall group cohesion (Johannesen et al. 2020). Tail beat frequency is particularly easy to observe from video recordings and has been found to correlate strongly with both swimming speeds and metabolic rates (Steinhausen et al. 2005, Hvas et al. 2021b). Hence, based on results from the present study, a tail beat frequency of 3.2 beats $\mathrm{s}^{-1}$ would suggest that the fish are swimming at their maximum sustained limit, while 2.5 beats s${ }^{-1}$ corresponds to the optimum CoT, and less than 2 beats $\mathrm{s}^{-1}$ signifies low swimming efforts that do not warrant concerns at any timescale.

Acknowledgements. This study was funded by the Research Council of Norway through the project SFI Exposed (237790).

\section{LITERATURE CITED}

Alsop DH, Wood CM (1997) The interactive effects of feeding and exercise on oxygen consumption, swimming performance and protein usage in juvenile rainbow trout (Oncorhychus mykiss). J Exp Biol 200:2337-2346

Beamish FWH (1978) Swimming capacity. In: Hoar WS, Randall DJ (eds) Fish physiology. Academic Press, New York, NY, p 101-187

*Beddow TA, McKinley RS (1999) Importance of electrode positioning in biotelemetry studies estimating muscle activity in fish. J Fish Biol 54:819-831 
Bell WH, Terhune LDB (1970) Water tunnel design for fisheries research. Technical Report No. 195. Fisheries Research Board of Canada, Nanaimo

Bjelland HV, Føre M, Lader P, Kristiansen D and others (2015) Exposed aquaculture in Norway. In: OCEANS 2015. Institute of Electrical and Electronics Engineers (IEEE) and Marine Technology Society (MTS), Washington, DC, p 1-10

Black EC (1958) Hyperactivity as a lethal factor in fish. J Fish Res Board Can 15:573-586

Bone Q, Kicenuik J, Jones DR (1978) On the role of different fibre types in fish myotomes at intermediate swimming speeds. Fish Bull 76:691-699

Brett J (1964) The respiratory metabolism and swimming performance of young sockeye salmon. J Fish Res Board Can 21:1183-1226

Brett JR (1965) The relation of size to rate of oxygen consumption and sustained swimming speed of sockeye salmon (Oncorhynchus nerka). J Fish Res Board Can 22: 1491-1501

Brett JR (1967) Swimming performance of sockeye salmon in relation to fatigue time and temperature. J Fish Res Board Can 24:1731-1741

Brown EJ, Bruce M, Pether S, Herbert NA (2011) Do swimming fish always grow fast? Investigating the magnitude and physiological basis of exercise-induced growth in juvenile New Zealand yellowtail kingfish, Seriola lalandi. Fish Physiol Biochem 37:327-336

Bui S, Dempster T, Remen M, Oppedal F (2016) Effect of ectoparasite infestation density and life-history stages on the swimming performance of Atlantic salmon Salmo salar. Aquacult Environ Interact 8:387-395

Burgetz IJ, Rojas-Vargas A, Hinch SG, Randall DJ (1998) Initial recruitment of anaerobic metabolism during submaximal swimming in rainbow trout (Oncorhynchus mykiss). J Exp Biol 201:2711-2721

Castro V, Grisdale-Helland B, Helland SJ, Kristensen T and others (2011) Aerobic training stimulates growth and promotes disease resistance in Atlantic salmon (Salmo salar). Comp Biochem Physiol A Mol Integr Physiol 160: 278-290

Christiansen J, Jobling M (1990) The behaviour and the relationship between food intake and growth of juvenile Arctic charr, Salvelinus alpinus L., subjected to sustained exercise. Can J Zool 68:2185-2191

Cotterell SP, Wardle CS (2004) Endurance swimming of diploid and triploid Atlantic salmon. J Fish Biol 65:55-68

Farrell AP, Johansen JA, Suarez RK (1991) Effects of exercise training on cardiac performance and muscle enzymes in rainbow trout, Oncorhynchus mykiss. Fish Physiol Biochem 9:303-312

Farrell AP, Thorarensen H, Axelsson M, Crockerd CE, Gamperl AK, Cech JJ Jr (2001) Gut blood flow in fish during exercise and severe hypercapnia. Comp Biochem Physiol A Mol Integr Physiol 128:551-563

Gansel LC, Rackebrandt S, Oppedal F, McClimans TA (2014) Flow fields inside stocked fish cages and the near environment. J Offshore Mech Arctic Eng 136:031201

Gentry RR, Froehlich HE, Grimm D, Kareiva P and others (2017) Mapping the global potential for marine aquaculture. Nat Ecol Evol 1:1317-1324

Herskin J, Steffensen JF (1998) Energy savings in sea bass swimming in a school: measurements of tail beat frequency and oxygen consumption at different swimming speeds. J Fish Biol 53:366-376
Holmer M (2010) Environmental issues of fish farming in offshore waters: perspectives, concerns and research needs. Aquacult Environ Interact 1:57-70

Hudson RCL (1973) On the function of the white muscles in teleosts at intermediate swimming speeds. J Exp Biol 58: 509-522

* Hvas M, Oppedal F (2017) Sustained swimming capacity of Atlantic salmon. Aquacult Environ Interact 9:361-369

*Hvas M, Oppedal F (2019) Influence of experimental set-up and methodology for measurements of metabolic rates and critical swimming speed in Atlantic salmon Salmo salar. J Fish Biol 95:893-902

*Hvas M, Folkedal O, Solstorm D, Vågseth T, Fosse JO, Gansel LC, Oppedal F (2017a) Assessing swimming capacity and schooling behaviour in farmed Atlantic salmon Salmo salar with experimental push-cages. Aquaculture 473:423-429

Hvas M, Folkedal O, Imsland A, Oppedal F (2017b) The effect of thermal acclimation on aerobic scope and critical swimming speed in Atlantic salmon, Salmo salar. J Exp Biol 220:2757-2764

* Hvas M, Karlsbakk E, Mæhle S, Wright D, Oppedal F (2017c) The gill parasite Paramoeba perurans compromises aerobic scope, swimming capacity and ion balance in Atlantic salmon. Conserv Physiol 5:cox066

Hvas M, Folkedal O, Imsland A, Oppedal F (2018) Metabolic rates, swimming capabilities, thermal niche and stress response of the lumpfish, Cyclopterus lumpus. Biol Open 7:bio036079

Hvas M, Folkedal O, Oppedal F (2021a) Fish welfare in offshore salmon aquaculture. Rev Aquacult 13:836-852

*Hos M, Folkedal O, Oppedal F (2021b) Heart rates of Atlantic salmon Salmo salar during a critical swim speed test and subsequent recovery. J Fish Biol 98:102-111

* Johannesen Á, Patursson Ø, Kristmundsson J, Dam S, Klebert P (2020) How caged salmon respond to waves depends on time of day and currents. PeerJ 8:e9313

Johansson D, Juell JE, Oppedal F, Stiansen JE, Ruohonen K (2007) The influence of the pycnocline and cage resistance on current flow, oxygen flux and swimming behaviour of Atlantic salmon (Salmo salar L.) in production cages. Aquaculture 265:271-287

Johansson D, Laursen F, Fernö A, Fosseidengen JE and others (2014) The interaction between water currents and salmon swimming behaviour in sea cages. PLOS ONE 9: e97635

Jones DR (1982) Anaerobic exercise in teleost fish. Can J Zool 60:1131- 1134

Jónsdóttir KE, Hvas M, Alfredsen JA, Føre M, Alver MO, Bjelland HV, Oppedal F (2019) Fish welfare based classification method of ocean current speeds at aquaculture sites. Aquacult Environ Interact 11:249-261

Kiceniuk JW, Jones DR (1977) The oxygen transport system in trout (Salmo gairdneri) during sustained exercise. J Exp Biol 69:247-260

Klebert P, Su B (2020) Turbulence and flow field alterations inside a fish sea cage and its wake. Appl Ocean Res 98: 102113

McKenzie DJ, Palstra AP, Planas J, MacKenzie S and others (2021) Aerobic swimming in intensive finfish aquaculture: applications for production, mitigation and selection. Rev Aquacult 13:138-155

Norin T, Clark TD (2016) Measurement and relevance of maximum metabolic rate in fishes. J Fish Biol 88: $122-151$ 
Ohlberger J, Staaks G, Hölker F (2006) Swimming efficiency and the influence of morphology on swimming costs in fishes. J Comp Physiol B 176:17-25

* Oldham T, Nowak B, Hvas M, Oppedal F (2019) Metabolic and functional impacts of hypoxia vary with size in Atlantic salmon. Comp Biochem Physiol A Mol Integr Physiol 231:30-38

Oppedal F, Dempster T, Stien L (2011) Environmental drivers of Atlantic salmon behaviour in sea-cages: a review. Aquaculture 311:1-18

Palstra A, van Ginneken V, van den Thillart G (2008) Cost of transport and optimal swimming speed in farmed and wild European silver eels (Anguilla anguilla). Comp Biochem Physiol A Mol Integr Physiol 151:37-44

Palstra AP, Mes D, Kusters K, Roques JAC and others (2015) Forced sustained swimming exercise at optimal speed enhances growth of juvenile yellowtail kingfish (Seriola lalandi). Front Physiol 5:506

Palstra AP, Kals J, Böhm T, Bastiaansen JWM, Komen H (2020) Swimming performance and oxygen consumption as non-lethal indicators of production traits in Atlantic salmon and gilthead seabream. Front Physiol 11:759

Randall DJ, Daxboeck C (1982) Cardiovascular changes in the rainbow trout (Salmo gairdneri Richardson) during exercise. Can J Zool 60:1135-1140

Remen M, Solstorm F, Bui S, Klebert P and others (2016) Critical swimming speed in groups of Atlantic salmon Salmo salar. Aquacult Environ Interact 8:659-664

Ricker WE (1975) Computation and interpretation of biological statistics of fish populations. Bull Fish Res Board Can 191:1-382

Solstorm F, Solstorm D, Oppedal F, Fernö A, Fraser TWK, Olsen RE (2015) Fast water currents reduce production performance of post-smolt Atlantic salmon Salmo salar. Aquacult Environ Interact 7:125-134

Editorial responsibility: Chris Noble,

Tromsø, Norway

Reviewed by: A. Palstra and 2 anonymous referees
Steinhausen MF, Steffensen JF, Andersen NG (2005) Tail beat frequency as a predictor of swimming speed and oxygen consumption of saithe (Pollachius virens) and whiting (Merlangius merlangus) during forced swimming. Mar Biol 148:197-204

Svendsen JC, Skov J, Bildsoe M, Steffensen JF (2003) Intraschool positional preference and reduced tail beat frequency in trailing positions in schooling roach under experimental conditions. J Fish Biol 62:834-846

* Timmerhaus G, Lazado CC, Cabillon NAR, Megård Reiten BK, Johansen LH (2021) The optimum velocity for Atlantic salmon post-smolts in RAS is a compromise between muscle growth and fish welfare. Aquaculture 532: 736076

Tudorache C, Viaenen P, Blust R, De Boeck G (2007) Longer flumes increase critical swimming speeds by increasing burst-glide swimming duration in carp Cyprinus carpio, L. J Fish Biol 71:1630-1638

Tudorache C, O'Keefe RA, Benfey TJ (2011) Optimal swimming speeds reflect preferred swimming speeds of brook charr (Salvelinus fontinalis Mitchill, 1874). Fish Physiol Biochem 37:307-315

Videler JJ (1993) Fish swimming, $1^{\text {st }}$ edn. Chapman \& Hall, London

Webb PW (1975) Hydrodynamics and energetics of fish propulsion. Bull Fish Res Board Can 190:1-158

*Weihs D, Keyes RS, Stalls DM (1981) Voluntary swimming speeds of two species of large carcharhinid sharks. Copeia 1981:219-222

*Wilson RW, Egginton S (1994) Assessment of maximum sustainable swimming performance in rainbow trout (Oncorhynchus mykiss). J Exp Biol 192: 299-305

*Wood CM, Turner JD, Graham MS (1983) Why do fish die after severe exercise? J Fish Biol 22:189-201

Submitted: September 25, 2020

Accepted: March 17, 2021

Proofs received from author(s): May 18, 2021 